\title{
Educação, Cultura Digital e Espaços Formativos
}

\section{TANIA MARIA HETKOWSKI}

Pós-doutorado em Informática na Educação (UFRGS). Professora Titular da Universidade do Estado da Bahia. Atua nos Programas de Pós-graduação Educação e Contemporaneidade (PPGEduC) e Gestão e Tecnologias Aplicadas à Educação (GESTEC). Líder do Grupo de Pesquisa GEOTEC. Pesquisa sobre TIC, Práticas Pedagógicas Inovadoras, Geotecnologias e espaços potenciais citadinos. ORCID: https://0000-0001-5793-7898. E-mail: taniah@uneb.br

\section{JOSEMEIRE MACHADO DIAS}

Doutora em Educação e Contemporaneidade (UNEB). Professora Adjunta da Universidade do Estado da Bahia. Atua no Programa de Pós-graduação Gestão e Tecnologias aplicadas à Educação (GESTEC) e na Graduação em Design. Vice-líder do Grupo de Pesquisa Geotecnologias, Educação e Contemporaneidade - GEOTEC. Pesquisa sobre Interação Humano Computador, Interfaces e Práticas Pedagógicas Inovadoras.

ORCID: https://0000-0002-8624-4641.E-mail: jmdias@uneb.br 


\section{EDUCAÇÃO, CULTURA DIGITAL E ESPAÇOS FORMATIVOS}

Este texto representa um esforço mútuo para (re)desenhar um diálogo sobre Educação e Cultura Digital. Um dos argumentos centrais deste escrito se traduz na ideia da Educação como prática transformadora e ato humano comprometido com o outro nos aspectos mais singulares da natureza humana, quais sejam a política, tecnologias, bens culturais, consciência econômica, formação escolar e bem-estar social. Aqui, também se pretende argumentar sobre a Cultura Digital e os processos formativos que os alunos da Educação Básica das redes públicas enfrentam em tempos de acesso exponencial aos instrumentos digitais, a uma gama incomensurável de informações e a velocidade que estas informações, são descartadas. Neste sentido, este escrito também desvela a função do professor como um Designer de Experiências de Aprendizagem (FLOOR, s/d) as quais não se limitam a determinadas tecnologias ou métodos de aprendizado, mas projeta a melhor experiência de aprendizagem com a melhor forma ou tecnologia para mediar as aprendizagens com seus alunos, confirmando que a tecnologia é um processo humano e criativo, material e imaterial, encarnados nas linguagens do saber e do fazer entre os homens.

Palabras Chave: Educação. Cultura Digital. Espaços Formativos.

\section{EDUCATION, DIGITAL CULTURE AND TRAINING SPACES}

This text represents a mutual effort to (re) design a dialogue about Education and Digital Culture. One of the central arguments of this text is the idea of Education as a transformative practice and a compromised human act with the other in the most singular aspects of human nature, such as politics, technologies, cultural goods, economic awareness, school education and social welfare. Here we also intend to argue about the Digital Culture and the formative processes that students, of the Basic Education of public networks, face in times of exponential access to digital instruments, to an immeasurable range of information and the speed that, this information, are discarded. In this way, this paper also reveals the function of the teacher as a Learning Experience Design (FLOOR, s/d), which is not limited to certain technologies or learning methods, but plan the best learning experience with the best mode or technology to mediate learning with his students, confirming that technology is a human and creative process, material and immaterial, embodied in the languages of knowledge and the languages of doing among men.

Keywords: Education. Digital Culture. Formative Spaces..

\section{EDUCACIÓN, CULTURA DIGITAL Y ESPACIOS DE FORMACIÓN}

Este texto representa un esfuerzo mutuo para (re) diseñar un diálogo sobre Educación y Cultura Digital. Uno de los argumentos centrales de este escrito es la idea de la educación como una práctica transformadora y un acto humano comprometido con el otro en los aspectos más singulares de la naturaleza humana, como la política, las tecnologías, los bienes culturales, la conciencia económica, la educación escolar y el bienestar social. Aquí también tenemos la intención de discutir sobre la Cultura Digital y los procesos formativos que enfrentan los estudiantes de Educación Básica de las redes públicas en tiempos de acceso exponencial a instrumentos digitales, una cantidad inconmensurable de información y la velocidad que, las informaciones, son descartadas. Por lo tanto, este documento también revela el papel del profesor como Designer de Experiencias de Aprendizaje (FLOOR, s/d), no limitado a ciertas tecnologías o métodos de aprendizaje, sino la persona que proyecta la mejor experiencia de aprendizaje con la mejor manera o tecnología para mediar el aprendizaje con sus estudiantes, confirmando que la tecnología es un proceso humano y creativo, material e inmaterial, encarnado en las lenguajes del conocimiento y el hacer entre los hombres.

Palabras Clave: Educación. Cultura Digital. Espacios de Formación..

P/Ulais Salvador, v. 4, n. 2, p. 11-25, mai./ago. 2019 


\section{EDUCAÇÃO, CULTURA DIGITAL E ESPAÇOS FORMATIVOS}

\section{Introdução}

Nesse ensaio, a Educação é entendida como prática transformadora e ato humano comprometido com o outro, caracterizados pelos processos de formação política, técnica, cultural, econômica, escolar e social, o qual encontra sinergia à Cultura Digital, à produção e uso de instrumentos digitais que compõem a vida e o fazer das crianças e adolescentes, dentro e fora dos espaços escolares.

Nesse sentido, a Cultura Digital, definida de forma embrionária por Gil (2013), é a Cultura da Contemporaneidade ${ }^{1}$ aberta a novas oportunidades de aprendizagens significativas no espaço escolar. O formato digital integra o cotidiano dos sujeitos escolares que se tornam protagonistas de construções comunicacionais, audiovisuais, interativas em redes, compartilhadas através de conteúdo, produzidas artística e culturalmente, que emergem outras singularidades e outros significados, os quais podem ser complexos ou efêmeros, mas são fundantes às reflexões e intervenções no ambiente escolar, entre alunos e professores, para além do conteúdo disciplinar.

A escola, embora saibamos das inúmeras dificuldades enfrentadas nas redes públicas de ensino do país, não pode se isentar das possibilidades que a tecnologia digital proporciona, colaborando de forma efetiva para o Capital Cultural dos seus sujeitos. Trata-se de um grande desafio redirecionar o movimento instituído nos processos de ensino e aprendizagem, com suas práticas que, na sua maioria, não mobilizam os sujeitos para interações que sejam prazerosas e motivadoras, culminando na descaracterização da escola como espaço de crescimento, desenvolvimento social e oportunidades no mundo da vida e do trabalho.

Embora professores e alunos vivam em uma cultura digital, com a utilização de smartphones, redes sociais, aplicativos, jogos e os mais variados recursos que desencadeiam novos comportamentos, consideramos um descompasso entre a realidade escolar e a utilização dos instrumentos tecnológicos nos processos de aprendizagem mais interativos. Esse é o descompasso é o grande desafio da educação na contemporaneidade e na cultura digital.

\footnotetext{
${ }^{1}$ A contemporaneidade, portanto, é uma singular relação com o próprio tempo, que adere a este e, ao mesmo tempo, dele toma distâncias; mais precisamente, essa é a relação com o tempo que a este adere através de uma dissociação e um anacronismo. (AGAMBEN, 2009, p. 59).
} 
A contemporaneidade tem como premissa considerar e entender o tempo do aluno, do professor, dos processos de ensino e aprendizagem, e da sinergia entre a técnica, a ciência e as relações sociais que, na escola, ampliam as capacidades cognitivas, as mediações entre os saberes, o uso das TIC e as potencialidades entre teoria e prática. Essa premissa corrobora com o pensamento hipertextual do sujeito e com a ampliação das habilidades motoras e cognitivas, das novas gerações, que conseguem fazer tudo ao mesmo tempo..., juntos.

Assim, a escola não pode se mostrar alheia a esse cenário contemporâneo, pois o espaço escolar precisa considerar a realidade exterior, superar a instrumentalização técnica, a bipolaridade entre escola e comunidade, a negação da experiência dos sujeitos, contrastando com o ambiente vivido por alunos e professores, cuja celeridade da comunicação e das interações está prenhe e presente na sala de aula.

Desta forma, compreendemos a práxis escolar como consciência de se reinventar, de buscar reflexões acerca das ações dos sujeitos, para transformar os modos de ser, agir, fazer e potencializar a cultura digital, neste caso, no espaço escolar. Nesse sentido, a pretensão desse ensaio é provocar uma discussão sobre Educação e Cultura Digital, destacando as possibilidades do uso das Tecnologias da Informação e Comunicação (TIC) nos processos formativos dos alunos da Educação Básica, em especial das redes públicas, espaço no qual o professor pode exercer uma função de Designer de Experiências de Aprendizagem (FLOOR, s/d), ampliando práticas, experiências e conhecimentos.

\section{Educação e Práticas Pedagógicas na Contemporaneidade}

Este texto convida o interlocutor contemporâneo para (re)pensar que é preciso ter coragem nos enfrentamentos destes tempos intempestivos, os quais exigem posicionamentos sobre Educação e sobre os direitos de aprender e ensinar, permitindo aos sujeitos pensar, criticar e arguir sobre o 'inoportuno' que acontece nos espaços escolares, cotidianamente e persistentemente.

Agamben (2009) enfatiza que fazer educação escolar é permitir buscar e se defrontar com o estranho, com o difícil e o 'inapropriado' para entender tempos obscuros que possibilitam atualizar e enxergar aquilo que está escondido e, que se revelam através das leituras, análises, sentidos e significados. Neste caso, a imersão das crianças e jovens na Cultura Digital e, nestes meandros contemporâneos, perceber que os espaços educacionais, em especial da Educação Básica, são germinais à capacidade criadora e inventiva. 
Para Levy (1998, p. 25),

Espaço do saber é o espaço da inteligência e do saber coletivos, não suprime os outros espaços, mas aglomera-os. Ele deve-se à velocidade da evolução, aparece como possibilidade da massa e produz novos saberes pelo surgimento das novas ferramentas disponíveis do ciberespaço.

Esse espaço de conhecimentos coletivo, comunidade escolar, é entendido como chão da escola, como instituição gestadora, germe e celeiro à fecundação de ideias, saberes e fazeres sistematizados, reconhecidos e potenciais à difusão e ampliação de práticas, vivências e de episteme, simultaneamente, com uma comunidade escolar que transbordada, mergulha e se encontra imersa nas/pelas tecnologias digitais no seu cotidiano de vida.

Neste ínterim, a Educação como ato político demanda respeito à autonomia do ser do educando um dos saberes apontados por Freire (2016, p. 56):

O respeito à autonomia e à dignidade de cada um é um imperativo ético e não um favor que podemos ou não conceder uns aos outros. Precisamente porque éticos podemos desrespeitar a rigorosidade da ética e resvalar para a sua negação, por isso é imprescindível deixar claro que a possibilidade do desvio ético não pode receber outra designação senão a de transgressão.

Diante do exercício da ética não podemos permitir a continuidade das desigualdades que marcam o momento em que vivemos, pontuadas por Bourdieu (1998) ao abordar sobre o Capital Cultural, destacando que a escola representa um lugar à manutenção das desigualdades a partir do momento em que a cultura e as vivências dos alunos não são consideradas quando da exploração dos conteúdos abordados. É preciso pensar a educação como prática de transformação associada a um pensamento de libertação e, neste contexto valorizar os processos colaborativos, os sentimentos de solidariedade, o respeito à dignidade humana e o cenário potencial desencadeado com o uso das Tecnologias de Informação e Comunicação (TIC) dentro e fora dos espaços escolares.

Neste sentido, referir-se às TIC e às exigências de práticas pedagógicas inovadoras requer redimensionar os processos e as narrativas que envolvem discursos de que os espaços da escola se distanciam da cultura digital. A cultura digital está na escola e no âmbito dos processos educativos, representa uma construção teórica de como as subjetividades são posicionadas, investidas e construídas como processo (in)consciente à complexidade das mudanças sociais e 
tecnológicas, da política de acesso e uso das TIC e; da legitimação dos instrumentos pelas novas gerações.

Logo, compreender as TIC no âmbito das práticas pedagógicas é localizá-las como instrumentos potencializadores à formação e à transformação das características opressoras da sociedade até então fixadas, bem como percebê-las como construções sociais, não restritas a usos eficientistas, mas produtoras de significados e sentidos para mobilização e superação de discursos positivistas, compondo novas práticas escolares associadas às demais práticas sociais que sustentam a condição humana do aluno e do professor.

Se a educação é uma prática que se desenvolve em contextos reais, as TIC, dentro dos espaços escolares, requerem uma perspectiva crítica à prática pedagógica dos professores, ampliando as linguagens através de uma rede contextual, assim como desvelar e possibilitar o entrelaçamento entre ensino, escola, comunidade e processos historicamente construídos, trazidos pelos alunos à essência da escola a partir de suas realidades vivificadas.

Significa dizer que essas práticas pedagógicas, na cultura digital, somente terão ressonâncias se envolverem as práticas sociais, políticas, educativas, filosóficas, econômicas, técnicas entre outras, as quais podem (re)significar as práticas de sala de aula. Nesse sentido, é necessário perceber o professor como um sujeito intelectual, preocupado e comprometido com a Educação como prática emancipadora, que considera o espaço da escola como esfera pública e democrática, que visa à restauração da comunidade e de valores compartilhados com ela, fomentando discursos entrelaçados aos imperativos democráticos de igualdade e justiça social.

A relação pedagógica é redimensionada pela própria realidade, pois nela se dialoga sobre o mundo e sobre a vida dos sujeitos, nela eclodem as exigências de formação e é nela, também, que os sujeitos atuam. Assim, as escolas não podem ser concebidas sem sua interação com os pressupostos da cultura digital, a qual exige ações mais abertas e interativas, com práticas mais coletivas, ligações e conexões estreitas entre professores e alunos e entre alunos e sociedade, articulações com diferentes projetos, valendo-se das possibilidades inerentes à convergência das tecnologias.

\section{Cultura Digital e Espaços Educativos}

A dinâmica sociocultural da sociedade contemporânea evidencia a presença e a fluidez da telemática, da informática e da cibernética em todos os processos da vida humana, as quais mudam as formas de ensinar, aprender, comunicar, relacionar e de praticar a arte de educar.

\footnotetext{
p/U] ais Salvador, v. 4, n. 2, p. 11-25, mai./ago. 2019
} 
Nesse contexto pulsante emerge a Cultura Digital, caracterizada pela presença das mídias, pela mudança de comportamentos, pela celeridade das informações e pela tele prontidão do tempo e espaço. De modo, que a Cultura Digital está agregada aos processos ideológicos, impregnada e enraizada aos preceitos da ciência, às inovações das técnicas, às metanarrativas otimistas ou pessimistas e às práticas transformadoras das sociedades, onde crianças e jovens vivem à atualização da cultura e das produções tecnológicas e humanas.

Na década de 90 o autor Manuel Castells (1990) anunciava o apogeu da Sociedade da Informação, destacando a diferenciação social e cultural, a crescente estratificação social, a integração de todos os tipos de mensagens e a captação de expressões culturais em sua diversidade através das mídias, multimídias, redes e potenciais digitais.

\begin{abstract}
Além disso, um novo sistema de comunicação que fala cada vez mais uma língua universal digital tanto está promovendo a integração global da produção e distribuição de palavras, sons e imagens de nossa cultura como personalizando-os ao gosto das identidades e humores dos indivíduos. As redes interativas de computadores estão crescendo exponencialmente, criando novas formas e canais de comunicação, moldando a vida e, ao mesmo tempo, sendo moldadas por ela. (CASTELLS, 1999, p. 22).
\end{abstract}

Essa emergência de se pensar outras formas, metodologias, estratégias e táticas para educar, ensinar e 'amparar' o aluno nos espaços da escola, ainda tradicional, e talvez pouco interessante se comparado à pulsante sociedade digital, acessível, incomensurável e deveras atraente, nela pulsam imagens, jogos, vídeos, textos, espaços interativos entre outras alegorias digitais. Para Lemos (2017, p. 13),

Estamos em meio a uma nova etapa na cultura digital com o desenvolvimento da Internet das Coisas (Internet of Things, IoT) e do Big Data. A IoT caracterizase por objetos ampliados infocomunicacionalmente, permitindo a coleta e tratamento de enormes quantidades de dados (Big Data), em uma emergente governabilidade algorítmica em diversas áreas da vida social. Essa conjunção está no bojo dos projetos de 'cidades inteligentes' (SMART CITIES).

Destacamos que a internet das coisas não se resume aos instrumentos, nem a autonomia dos mesmos no que se refere a situações representativas, simuladas ou vividas entre sujeitos nas suas relações sociais. Assim, é temeroso pensar que os potenciais algorítmicos poderão incidir em um novo discurso sobre eficiência instrumental, provocando mais um equívoco acerca das 
possibilidades transformadoras desta nova geração, a qual diante de um contrato social estaria em perigo.

\section{Desafios para a Educação na Cultura Digital}

Os desafios deste século nos remetem visitar um passado próximo, o qual nos (de)monstra argumentações e provocações acerca da Educação e Cultura Digital. No Brasil, a internet foi liberada para acesso comercial em 1995, antes desse fato a rede era restrita a poucos espaços como Universidades Federais e Centros de Pesquisa, com acesso limitado à população e aos serviços oferecidos.

A internet comercial abriu um leque de possibilidades a ser explorado em todos os seguimentos da sociedade, modificando de forma significativa as interações dos sujeitos, a forma de comunicação e alterando comportamentos e, foi com o surgimento dos navegadores gráficos, na realidade brasileira, como o Netscape e o Internet Explorer que a internet demarcou sua popularidade, permitindo o uso e acesso de todos seus recursos por sujeitos de diferentes idades, escolaridades, níveis econômicos, sociais e culturais.

A inserção na internet e a apresentação das suas funcionalidades, aos seus públicos-alvo, rapidamente se tornou uma ordem para os diversos segmentos da sociedade, cuja presença nos ambientes era obrigatória para se manter e demonstrar competitivo, mesmo que fosse apenas o seu logotipo com endereço e telefone ou uma imagem informando que o ambiente estava em construção.

O novo ambiente digital, acessado principalmente por meio dos navegadores, era composto por informações centralizadas em servidores em uma arquitetura de rede denominada de clienteservidor, migrando posteriormente para ambientes colaborativos como Wikis, Blogs, Redes Sociais, Plataformas de compartilhamento de Vídeo, dentre vários outros recursos que logo foram denominados de Web 2.0 para diferenciar-se do ambiente anterior, um ambiente estático com pouca interação, em que o 'usuário' era concebido como espectador ou navegante da rede.

$\mathrm{Na}$ web 2.0 o usuário tornou-se um ator e produtor criativo imerso em um ambiente caracterizado, principalmente, pela colaboração. Desse modo, a Web inaugura seu terceiro momento denominado Web 3.0 que, embora, não exista um consenso pela sua definição, se mostra convergente com os fundamentos da inteligência artificial, na melhoria da performance sobre as informações que circundam a rede e no atendimento eficaz às solicitações dos sujeitos. 
Rememorar os avanços da internet é fundamental para refletirmos sobre os desafios da educação na contemporaneidade e na cultura digital, pois os mais diversos segmentos da sociedade tiveram processos modificados com os avanços das tecnologias e muitos precisaram se reinventar para sobreviver, como as agências de viagens, altamente impactadas pelos serviços e recursos disponibilizados na web. Hoje os internautas são seus próprios agentes, efetivando compras, criando roteiros, escolhendo hospedagens e outros itens necessários à sua viagem. Essas facilidades são permitidas devido às imagens de satélites que permitem conhecer, em tempo real, o espaço desejado e planejado para trabalho, visita ou férias.

Esse exemplo aponta para a necessidade de um movimento que permite reinventar os processos educacionais e transformar a função do professor para atendimento de alunos que demandam, cada vez mais, conexões e não se condescendem com o distanciamento do seu "ecossistema" - metáfora para o ambiente hiperconectado em que vivem esses sujeitos. A escola não pode continuar sendo um lugar de manutenção das desigualdades sociais,

[...] para que sejam favorecidos os mais favorecidos e desfavorecidos os mais desfavorecidos, é necessário e suficiente que a escola ignore, no âmbito dos conteúdos do ensino que transmite, dos métodos e técnicas de transmissão e dos critérios de avaliação, as desigualdades culturais entre as crianças das diferentes classes sociais. (BOURDIEU, 1998, p.59).

Assim, acreditamos que um dos principais desafios para a educação na contemporaneidade é entender a diversidade cultural dos sujeitos, ampliando as possibilidades de aprendizagem respeitando as suas origens e os seus capitais culturais. Com base neste entendimento, é possível utilizar as TIC na produção e ressignificação de conhecimentos que se apresentam vivos e pululantes no cotidiano das crianças e adolescentes, ou seja, dos alunos em fase de formação na Educação Básica.

Outro desafio é o professor deixar de ser o centro do processo de ensino e aprendizagem e socializar suas experiências e conhecer as experiências dos alunos, de valorizar sua história de vida e a história e vida dos seus alunos. Esse ato demanda entender e incorporar o processo formativo, dos sujeitos da escola, como germinador nos espaços e nos lugares da escola e da sociedade, emaranhados à cultura digital. O professor se insere em um espaço colaborativo, pois a rapidez e efemeridade do ambiente digital são constantes, o que inviabiliza uma inserção e domínio dos recursos demandados pelos alunos e isso provoca um lag entre a tecnologia do aluno e a do professor (DIAS, HETKOWSKI e PEREIRA, 2013). 
Lag, originária do ambiente computacional, indica certo atraso no domínio dos recursos e das tecnologias pelos alunos e pelos professores - quando o professor não consegue acompanhar a rapidez com que as trocas ocorrem e os novos modos de agir são incorporados no cotidiano dos alunos. Para os alunos as mudanças ocorrem de forma natural e os recursos se tornam obsoletos, e isso reforça a necessidade de uma nova postura do professor, capaz de conciliar as novidades tecnológicas das exigências da escola.

Alguns pesquisadores e autores como LIRA (2018), SILVEIRA (2016), ALLAN (2015) GABRIEL (2013), MORAN (2013) abordam sobre as necessidades do professor se reinventar e sobre estratégias às mudanças significativas na proposta de ensino e aprendizagem com seus alunos. Mas, enfatizamos que o maior desafio é superar estratégias pontuais. É preciso uma efetiva mudança nas políticas públicas de formação e de valorização do professor, nos pressupostos metodológicos e epistemológicos durante sua formação, na relação entre teoria e prática que atenda as realidades das redes e, na atuação comprometida com o outro nos aspectos mais singulares da natureza humana, ou seja, urge pensarmos em um professor como Projetista de Experiências de Aprendizagens, ou Designer de Experiências de Aprendizagem (FLOOR, $\mathrm{s} / \mathrm{d}$ ), implicado com seus alunos e com as comunidades.

Chamamos atenção que Design de Experiências de Aprendizagem, do inglês Learning Experience Design - LX, tem sido constantemente confundido com a denominação E-learning ou Design Instrucional. Para Floor (s/d, s/p), nos seus escritos, há clareza de que,

[...] o design de experiência de aprendizagem não se limita a certas tecnologias ou tipos de aprendizado. O objetivo é projetar a melhor experiência de aprendizagem possível e escolher a forma ou tecnologia que funciona melhor para o aluno em uma situação específica e / ou em um determinado momento. Se a tecnologia é de séculos ou de ponta é irrelevante. Se funciona, funciona! (Tradução nossa).

Essa denominação encontra ressonâncias no entendimento sobre Educação, Cultura Digital e processos formativos o mundo da vida e da escola aos alunos da Educação Básica. Assim, pensar na postura de um professor como Designer de Experiências de Aprendizagem permite compreender que tecnologia utilizada não precisa ser uma tecnologia digital, uma vez que a riqueza da experiência está nos processos de ensino e aprendizagem entre os sujeitos, independente do tipo de tecnologia. 
A tecnologia pode ser entendida como um processo humano e criativo, que envolve elementos materiais (instrumentos e técnicas) e imateriais (simbólicos e cognitivos), encarnados nas linguagens do saber e do fazer entre os homens. Essa gênese traz, na história do homem, um empenho visceral à transformação da natureza, na geração de benefícios às comunidades, na simplificação da vida cotidiana, nas formas de registro, nos modos de comunicação e, no conhecimento produzido.

Entendemos que a Cultura Digital não é um corte no tempo ou na história, mas é tecida pelo conhecimento produzido e ampliado, pela continuidade das ações e conquistas realizadas por homens e mulheres e, pelos movimentos de trocas e compartilhamentos mediados por diferentes técnicas ou instrumentos tecnológicos. Ou seja, a ausência de recursos tecnológicos digitais não pode privar os sujeitos das vivências associadas à cultura digital e isso incide no planejamento do professor, nas estratégias que serão utilizadas em sala de aula e no tipo de experiência e resultados que são esperados. Para Freire (2016, p.83-84), o bom professor,

(...) é o que consegue, enquanto fala, trazer o aluno até a intimidade do movimento de seu pensamento. Sua aula é assim um desafio e não uma "cantiga de ninar". Seus alunos cansam, não dormem. Cansam porque acompanham as idas e vindas de seu pensamento, surpreendem suas pausas, suas dúvidas, suas incertezas.

Não estamos negando o uso e o acesso aos instrumentos digitais; ao contrário, como dizia Marques, na década de 90, devemos levar a escola para o computador, porque os alunos levam para a escola tudo o que conhecem, descobrem, inventam e criam nos ambientes digitais, em especial nos serviços oferecidos pela Web. Nesse sentido, Freire (2016) sinaliza que a escola e os professores precisam para dar início à liberdade e autonomia nos caminhos da aprendizagem significativa aos sujeitos escolares; e Marques (1999) demarca que as tecnologias digitais permitem a continuidade dessa liberdade e autonomia para aprender e ensinar, colaborativamente.

Para superar os desafios e a laboriosa mudança de postura do professor, deveríamos ter uma política de formação continuada para que esse Design de Experiências de Aprendizagem pudesse vivenciar aproximações tecnológicas e transformá-las em experiências possíveis, pois assumir uma mudança de postura é um desafio que exige colaboração, solidariedade, sabedoria e investimentos para a Educação Brasileira. 


\section{Considerações Finais}

Não poderíamos chegar às considerações deste texto sem destacar as críticas, os entraves e as conquistas que tivemos na história da Educação; em destaque a década de 90, período que o cenário brasileiro sinalizou a necessidade de se pensar políticas públicas para o uso das TIC na educação. Esse tema trouxe muitas inquietações, discussões, desafios e mudanças, as quais foram evidenciadas nos Parâmetros Curriculares Nacionais, na Lei de Diretrizes e Bases/96, nas Diretrizes de Formação de Professores entre outros documentos que, na ocasião, expunham a preocupação em torno da cultura digital, da cibernética e das potencialidades da internet na vida dos alunos e professores nos espaços escolares.

De modo que o fim do século XX foi marcado por firmes críticas de inúmeros pesquisadores, dentre eles Lüdke (1999) ao destacar que o grande problema da Educação é a ausência da participação dos professores na definição de políticas e programas para a Educação. Sujeitos estes ignorados e, quando falam, suas vozes não têm ressonâncias, são tratados como meros executores de pacotes prontos de "cima para baixo". Nesse derradeiro século, a Proposta de Diretrizes para Formação Inicial de Professores da Educação Básica exigiu na formação dos professores o desenvolvimento de competências, as quais deveriam orientar e envolver os saberes profissionais, isto é, saber escolar a ser ensinado, saber didático a ser repassado, saber tácito que acompanha a transmissão para um desempenho desejado, cujo desempenho está relacionado ao saber fazer e não ao conhecimento reflexivo. A competência reforçou a formação e a narrativa dos professores executores e, usurpou a formação do professor intelectual.

As reformas educacionais mediadas pelo Ministério de Educação (MEC), naquele tempo, demonstravam o início do desmonte do ensino público e, consequente, incentivaram a privatização das escolas, como por exemplo: propostas de escolas cooperativas, adoção de escolas por empresas, escolas organizadas e assumidas pelas comunidades. Nos anos 2000 novas promessas e perspectivas de novos horizontes para a Educação, abertura de universidades públicas no interior dos estados, ampliação de vagas para formação de professores, investimento em ciência e tecnologia, propostas e projetos para uso de TIC na escola e, o cumprimento do Art. 206 e respeito à Constituição Federal de 1988,

I - igualdade de condições para o acesso e permanência na escola; II

- liberdade de aprender, ensinar, pesquisar e divulgar o pensamento, a arte e o saber; III - pluralismo de ideias e de concepções pedagógicas, e coexistência de instituições públicas e privadas de ensino; IV 
- gratuidade do ensino público em estabelecimentos oficiais; V - valorização dos profissionais do ensino, garantidos, na forma da lei, planos de carreira para o magistério público, com piso salarial profissional e ingresso exclusivamente por concurso público de provas e títulos; VI - gestão democrática do ensino público, na forma da lei; VII - garantia de padrão de qualidade. (BRASIL, CF/1988).

Atrelados ao cumprimento da $\mathrm{CF} / 1988$, vivenciamos, nestas duas últimas décadas, discussões e ações sobre cidadania, solidariedade planetárias, superação das desigualdades, eliminação das diferenças econômicas e culturais, desenvolvimento de ciência e tecnologia nas diversas áreas de conhecimento entre outras possibilidades essenciais que presumem a cidadania integral, garantindo, ao sujeito, plenos direitos sociais, políticos, culturais, econômicos e educacionais. Período que demonstrou avanços aos potenciais dos espaços virtuais; aos saberes emergentes em circulação; as comunidades pensantes e autorais; ao respeito à diversidade de pensamento; a ampliação de acesso à internet por alunos e professores; a valorização dos potenciais das tecnologias convencionais e digitais e; a invenção de novas formas, metodologias e estratégias para garantir a liberdade de expressão e de criação nos ambientes virtuais pelos jovens, em especial nos espaços da web.

Hoje, mesmo com muito entusiasmo em cada palavra lançada neste escrito sobre "Educação, Cultura Digital e Espaços Formativos", contabilizamos, no presente (des)governo, o desmoronamento do Ministério de Educação e Cultura (MEC); a repugnância dos representantes deste Ministério pela Escola e pela Educação; a aversão pelos pobres, negros, indígenas, homossexuais e outras minorias que são a maioria da população brasileira desprovida; os cortes nos investimentos para Educação Básica; a desqualificação e a perseguição aos professores de todos os níveis de ensino e; a ameaça e tirania contra os princípios da CF/1988 acerca da liberdade de pensamento, da coexistência do pluralismo de concepções pedagógicas, do princípio democracia nas escolas e do acesso ao ensino público e gratuito.

Todos estes fatores influenciam o cenário da Educação Brasileira, a qual está enfrentando um período perscrutador, indigno e aviltante; por isso, precisamos planejar, objetivar e efetivar mudanças drásticas na maneira de pensar e fazer Educação, com apoio das TIC. As tecnologias digitais, em especial, podem exercer funções instituintes, pois agem nos espaços banais, vivos, criativos e autorais e são potenciais aos alunos e professores, coletivamente e colaborativamente, encontrar novas formas de burlar o sistema para manter viva a esperança, o futuro e a Educação Brasileira. 
Os desafios são muitos, mas o acesso às tecnologias e as suas possibilidades, na Educação, podem e devem ser elementos fundamentais para a preparação dos sujeitos para os desafios do mundo contemporâneo. Não podemos nos isentar e afastar as possibilidades do pensamento computacional, da necessidade do entendimento de programação, da Realidade Virtual e da Realidade aumentada e, incorporá-los ao ambiente escolar e aos processos formativos dos alunos e professores. Saber usar as tecnologias digitais e, principalmente, desejar usá-la é abrir-se para novas e significativas experiências de aprendizagem, de vida e de mundo.

\section{REFERÊNCIAS}

AGAMBEN, G. O que é contemporâneo? E outros ensaios. (Trad. Vinicius Nicastro Honesko). Chapecó: Argos, 2009.

\section{ALLAN, L. Escola.com. Como as novas tecnologias estão transformando a educação na}

Prática. São Paulo. Figurati. 2015.

ARDOINO, J. Abordagem multirreferencial (plural) das situações educativas e formativas. Em J. G. Barbosa (Coord.). Multirreferencialidade nas ciências e na educação (pp. 24-41). São Carlos: Editora da UFSCar, 1998.

BOURDIEU, P. Escritos de Educação. Petrópolis: Vozes, 1998.

CASTELLS, M. Sociedade em Rede. (Trad. Roneide Venâncio Majer). São Paulo: Paz e Terra, 1999.

DIAS, J. HETKOWSKI, T. PEREIRA. T. Entrelaçando possibilidades de aproximação das tecnologias dos sujeitos da aprendizagem: as experiências do Projeto Notas de Aula. VII Colóquio Internacional de Educação e Contemporaneidade. São Cristóvão - Sergipe. 2013. ISSN 1982 - $3657<$ https://ri.ufs.br/bitstream/riufs/10271/42/41.pdf> Acesso em: jul 2019.

FLOOR, N. Learning Experience Design. Disponível em: $<$ http://learningexperiencedesign. com/the-three-main-misconceptions-about-learning-experience-design/> Acesso em: julho de 2019.

FREIRE, P. Pedagogia da autonomia: saberes necessários à prática educativa. 53 ed. São Paulo: Paz e Terra, 2016.

GABRIEL, M. Educar. A Revolução Digital na Educação. São Paulo. Saraiva. 2013. 
GIL, G. Aula Magna na USP - Universidade de São Paulo. In: ALMEIDA, Armando; ALBERNAZ, Maria Beatriz; SIQUEIRA, Maurício. (Org.) Cultura pela palavra: coletânea de artigos, entrevistas e discursos dos ministros da Cultura 2003-2010. Rio de Janeiro, Versal, 2013.

LEMOS, A. Visibilidade e contrato social em cidades inteligentes: análise preliminar de Glasgow, Curitiba e Bristol. In: MEHL, J. P.; SILVA, S. P. Cultura digital, internet e apropriações políticas: experiências, desafios e horizontes. Rio de Janeiro: Folio Digital, Letra e Imagem, 2017. p. 13-28.

LÉVY, P. A Inteligência Coletiva: por uma antropologia do ciberespaço. (Trad. Luiz Paulo Rouanet). São Paulo: Loyola, 1998.

LIRA, B. C. Práticas Pedagógicas para o Século XXI. A Sócio Interação Digital e o Humano ético. Petrópolis. Editora Vozes. 2018.

LÜDKE, Menga, MOREIRA, Antonio Flávio e CUNHA, Maria Isabel. Repercussões de tendências internacionais sobre a formação dos nossos professores. In: Revista Educação e Sociedade: Formação de profissionais da educação - políticas e tendências. Campinas: CEDES, n 69, 1999

MARQUES, Mario Osorio. A Escola no Computador: Linguagens Rearticuladas, Educação outra. Ijui: INIJUI, 1999.

MORAN, J. M. Ensino e aprendizagem inovadores com apoio de tecnologias In. MORAN, José Manuel, MASETTO, Marcos \& BEHRENS, Marilda. Novas tecnologias e mediação pedagógica. 21 ed. São Paulo: Papirus, 2013.

SILVEIRA, F. Design e Educação: Novas abordagens. In. MEGIDO, Victor (Org). A Revolução do Design. Conexões para o Século XXI. São Paulo. Editora Gente. 2016.

Enviado em: 20 de julho de 2019

Apreciado em: 30 de julho de 2019

Inserido em: 01 de agosto de 2019 